\title{
ARTHROSCOPICALLY-ASSISTED ROTATOR-CUFF REPAIR
}

\author{
STEPHEN H. LIU
}

From the University of California, Los Angeles, USA

We reviewed 44 patients with 44 full-thickness rotatorcuff tears at an average of $\mathbf{4 . 2}$ years after arthroscopically-assisted repair. There were 25 women and 19 men aged between 35 and 76 years (average 58); $35 \%$ of the shoulders had other intra-articular lesions.

Most of the patients ( $85 \%$ ) had been discharged from hospital immediately after the operation. The result was rated good or excellent in $84 \%, 88 \%$ of the patients were satisfied, and $64 \%$ of the athletes returned to their previous sports. The size of the tear was a determining factor in the outcome.

J Bone Joint Surg [Br] 1994; 76-B:592-5.

Received 17 November 1993; Accepted 23 December 1993

Recent improvement in shoulder arthroscopy has enabled us to appreciate better the spectrum of rotator-cuff injuries and to treat these lesions by less invasive techniques. The early results of arthroscopically-assisted rotator-cuff repair were promising (Levy, Uribe and Delaney 1990; Warner, Altchek and Warren 1991). Levy et al (1990) reported $80 \%$ good or excellent results in 25 patients followed for at least one year, and Warner et al (1991) reported 13 good or excellent results in 17 patients followed for two years with 11 of 12 athletes returning to their previous sports.

We now present our experience of 44 arthroscopically-assisted rotator-cuff repairs.

\section{PATIENTS AND METHODS}

Between January 1987 and January 1991, 48 patients had 52 arthroscopically-assisted repairs for chronic fullthickness rotator-cuff tears. We were able to evaluate 44 of these patients ( 44 repairs) at a minimum of two years after operation. There were 25 women and 19 men. Their average age was 58 years ( 35 to 76 ). The dominant arm was involved in 29 patients.

The indications for surgery were persistent pain and/ or functional disability which did not improve after six months of conservative treatment. In all of them full-

S. H. Liu, MD, Assistant Professor

Department of Orthopaedic Surgery, UCLA School of Medicine, CHS 76119, 10833 LeConte Avenue, Los Angeles, California 90024, USA.

C1994 British Editorial Society of Bone and Joint Surgery 0301-620X/94/4809\$2.00 thickness rotator-cuff tears had been shown by preoperative arthrography. All the operations were performed at the UCLA affiliated medical centres or the Hugheston Orthopaedic Clinic.

Operative technique. A standard shoulder arthroscopy is performed with the patient in the lateral position. The whole glenohumeral joint is inspected and concomitant lesions are dealt with. The extent of the rotator-cuff tear is graded as less than $1 \mathrm{~cm}, 1$ to $3 \mathrm{~cm}, 3$ to $5 \mathrm{~cm}$, or $>5 \mathrm{~cm}$. The edges of the tear are debrided, the arthroscope is passed into the subacromial bursa and the coracoacromial ligament is divided. Next, a burr is used to make a bony trough on the greater tuberosity. Three or four size 0 polydioxanone sutures (Ethicon, Somerville, New Jersey) are placed in the proximal edge of the torn tendon using an arthroscopic suture passer (Concept, Linvatec Corp, Largo, Florida) via the anterolateral portal (Fig. 1).

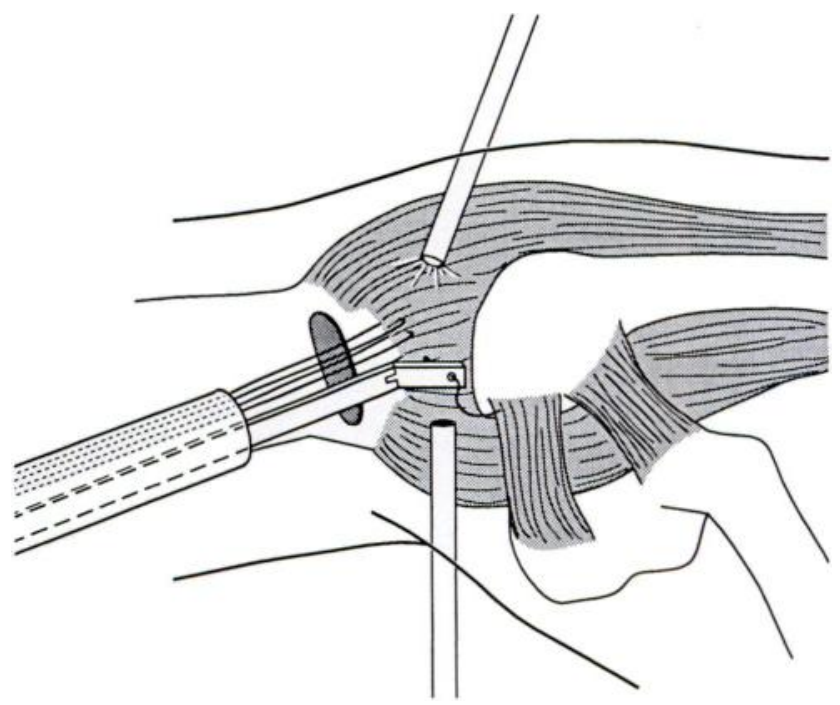

Fig. 1

Arthroscopic placement of sutures at the proximal edge of the torn cuff to facilitate mobilisation

The arm is then placed by the patient's side and the repair is completed through a small transverse incision which incorporates the anterolateral portal. The deltoid muscle is split for 2 to $4 \mathrm{~cm}$ longitudinally through the cleft created by the anterolateral portal. The split must not extend more than $5 \mathrm{~cm}$ from the acromion to avoid injury to the axillary nerve. The torn edge of the cuff can now be seen and is pulled laterally by tension on the sutures. 
Once the cuff can be brought to the bony trough without too much tension, four bone holes are made with a towel clip. Three non-absorbable mattress sutures are passed through the torn cuff which is pulled into the bony trough, and the sutures are tied through the bone holes (Fig. 2).

Postoperatively, the shoulder is immobilised in a $45^{\circ}$ abduction splint for three weeks, followed by a sling for three weeks. Rehabilitation is started on the first day and passive range-of-motion exercises are used for the first three weeks, followed by actively-assisted exercises during the fourth week. At six weeks resistance exercises are started, progressing to unrestricted activities at three to four months.

Data analysis. The average follow-up was 4.2 years $(2.5$ to 6.1). Function was evaluated using the UCLA shoulder rating scale (Ellman, Hanker and Bayer 1986) (Table I). Pain and function were rated on a scale of 1 to 10 points, 1 being the worst result. The overall result was graded as follows: excellent, 34 to 35 points; good, 29 to $33 ;$ and poor, less than 29. Active range of motion and muscle strength in forward flexion, abduction, and external rotation were also measured by the same physiotherapist both pre- and postoperatively.

We compared the patients' preoperative and postoperative scores for all of these measurements. Correlations between the size of the tear repaired, the functional outcome and the ability to return to the previous sport were made. A non-parametric (Kruskal-Wallis) test was used for these comparisons. A $p$ value of $<0.05$ was considered significant.

\section{RESULTS}

UCLA shoulder rating. All patients improved after surgery. The average pre- and postoperative scores were 10.5 and 32.7 respectively $(\mathrm{p}=0.001)$. Overall, $82 \%$ of the patients achieved excellent or good results and $88 \%$ were satisfied. The mean postoperative scores improved for each of the subcategories of pain, range of motion, function, and strength $(p<0.05)$. The more specific ranges of motion and strengths measured also improved consistently: forward flexion from $110^{\circ}$ to $157^{\circ}$; abduction from $100^{\circ}$ to $155^{\circ}$; and external rotation from $37^{\circ}$ to $50^{\circ}$ $(\mathrm{p}<0.05)$. The average gain in external rotation was $18^{\circ}$ ( 7 to 38 ), in forward flexion $45^{\circ}$ (25 to 55), and in abduction, $40^{\circ}$ (20 to 50). All patients improved at least one grade on manual strength testing. The average preoperative and postoperative strength gradings were: external rotation, 3.3 and 4.3; forward flexion, 3.4 and 4.5; abduction, 3.2 and 4.5.

Size of tear and functional outcome. Overall, there was a good or excellent functional outcome in $84 \%(37 / 44)$ of patients. This was seen in all those $(8 / 8)$ who had small tears, in 15 of the 17 with moderate tears, in 12 of the 15 with large tears, and in two of the five with massive tears. No significant differences were observed between the small, moderate, and large tears. Significant differences

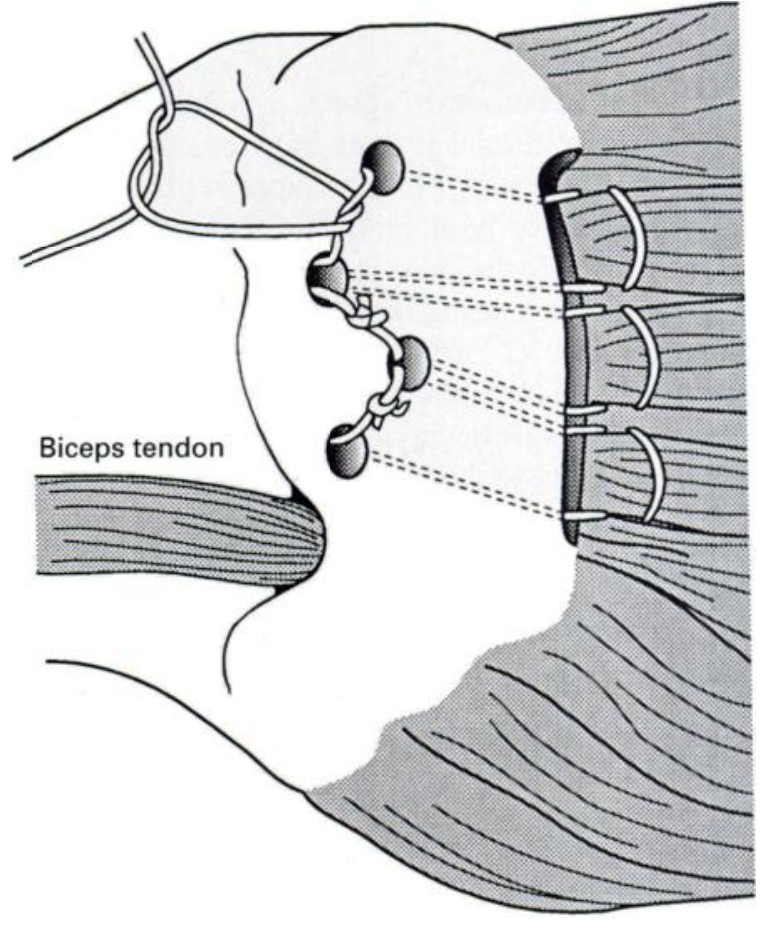

Fig. 2

Three mattress sutures are passed through the torn cuff and tied through four bone tunnels.

Table I. UCLA shoulder rating scale

\begin{tabular}{|c|c|}
\hline & Score* \\
\hline \multicolumn{2}{|l|}{ Pain } \\
\hline Present always and unbearable; strong medication frequently & 1 \\
\hline Present always, but bearable; strong medication occasionally & 2 \\
\hline $\begin{array}{l}\text { None or little at rest, present during light activities; salicylates } \\
\text { frequently }\end{array}$ & 4 \\
\hline $\begin{array}{l}\text { frequently } \\
\text { Present during heavy or particular activities only; salicylates }\end{array}$ & 4 \\
\hline $\begin{array}{l}\text { Present during heavy or particular activities only; salicylates } \\
\text { occasionally }\end{array}$ & 6 \\
\hline Occasional and slight & 8 \\
\hline None & 10 \\
\hline \multicolumn{2}{|l|}{ Function } \\
\hline Unable to use limb & 1 \\
\hline Only light activities possible & 2 \\
\hline Able to do light housework or most activities of daily living & 4 \\
\hline $\begin{array}{l}\text { Most housework, shopping, and driving possible: able to do hair } \\
\text { and to dress and undress, including fastening bra }\end{array}$ & 6 \\
\hline Slight restriction only; able to work above shoulder level & 8 \\
\hline Normal activities & 10 \\
\hline \multicolumn{2}{|l|}{ Active forward flexion } \\
\hline$>150^{\circ}$ & 5 \\
\hline $120^{\circ}$ to $150^{\circ}$ & 4 \\
\hline $90^{\circ}$ to $120^{\circ}$ & 3 \\
\hline $45^{\circ}$ to $90^{\circ}$ & 2 \\
\hline $30^{\circ}$ to $45^{\circ}$ & 1 \\
\hline$<30^{\circ}$ & 0 \\
\hline \multicolumn{2}{|l|}{ Strength of forward flexion (manual muscle testing) } \\
\hline Grade 5 (normal) & 5 \\
\hline 4 (good) & 4 \\
\hline 3 (fair) & 3 \\
\hline 2 (poor) & 2 \\
\hline 1 (muscle contraction) & 1 \\
\hline 0 (nothing) & 0 \\
\hline \multicolumn{2}{|l|}{ Satisfaction of the patient } \\
\hline Satisfied and better & 5 \\
\hline Satisfied and worse & 0 \\
\hline
\end{tabular}

* maximum score 35 points 
were observed between these tears and the massive tear group ( $\mathrm{p}<0.05)$.

Size of tear and return to sports. Overall, $64 \%(14 / 22)$ of the patients returned to their previous sports. Sports were resumed by $80 \%(4 / 5)$ of those with small tears, $78 \%(7 / 9)$ of those with moderate tears, $50 \%(3 / 6)$ of those with large tears, and by none $(0 / 2)$ of those with massive tears. Comparing the different sports, five of the seven swimmers, six of the ten golfers, and three of the five tennis-players returned to their sport.

Duration of hospital stay. All the patients stayed in hospital less than 48 hours after operation, 37 of them staying less than 24 hours. Of the seven patients who stayed longer than 24 hours, two had nausea and fever, two needed strong analgesics, and three lived far away. They were all discharged by the third day after surgery.

Associated pathology. Overall, 15 patients had intraarticular pathology, seven had labral tears, five had a tear of the biceps tendon, two had synovitis, and one had loose bodies.

Complications. Three complications were encountered. Two patients with massive tears had postoperative frozen shoulder syndrome. In one this resolved after prolonged physical therapy and the other required manipulation under anaesthesia. One patient had a superficial wound infection which resolved with local treatment. Two patients developed impingement syndrome, one from acromioclavicular degeneration two to five years after surgery, and one from bony spurs four years after surgery. Both patients had had small tears repaired, and no rotatorcuff tear was seen during subsequent arthroscopic acromioclavicular resection. No patient had a symptomatic rerupture.

\section{DISCUSSION}

The surgical management of full-thickness rotator-cuff tears continues to be controversial. Most authors have reported good results from open repair and acromioplasty (Neviaser, Neviaser and Neviaser 1978; Cofield 1985; Hawkins, Misamore and Hobeika 1985; Ellman, Hanker and Bayer 1986; Rockwood and Burkhead 1988; Cofield, Hoffmeyer and Lanzer 1990) and some have had equally good results with arthroscopic debridement and subacromial decompression, without repairing the cuff (Burkhart 1990; Cofield et al 1990; Levy, Gardner and Lemak 1991; Ogilvie-Harris and Demaziére 1993).

Recent advances in shoulder arthroscopy have improved the methods of evaluation and management of rotator-cuff disease, especially in stage-II and stage-III impingement lesions and many authors have reported good results from arthroscopic subacromial decompression and debridement of partial tears (Post and Cohen 1985; Gartsman 1990; Ellman and Kay 1991; Snyder et al 1991; Ellman, Kay and Wirth 1993). There have, however, been few studies of arthroscopically-assisted rotator-cuff repair. The technique of Levy et al (1990) involved either arthroscopically-placed sutures or a minimal deltoid-splitting technique. All their patients with small or moderate tears and $71 \%$ of those with large or massive tears had a good outcome. Warner et al (1991) reported good or excellent results in 13 of their 17 patients; eight of the nine tennis-players and all the three golfers returned to their previous sports but no correlation between the size of the tear and the functional outcome was mentioned.

Our study showed that $82 \%$ of the patients had good or excellent results and that $88 \%$ of the patients were satisfied. The size of the tear seemed to be a determining factor in the functional outcome; the small and moderate tears did better than the large and massive tears. The patients' satisfaction, however, did not seem to relate to the size of the tear repaired; those with small, moderate, and large tears were equally satisfied.

In this series 22 of the 44 patients were recreational athletes, including seven swimmers, ten golfers, and five tennis-players. Fourteen were able to return to their sports (five of seven swimmers, six of ten golfers, and three of five tennis-players). Again, the size of the tear repaired was a determining factor. Open rotator-cuff repair is known to have reliable results and to allow most athletes to return to their sports. Returning to overhead throwing or racquet sports, however, is less certain (Ellman et al 1986; Tibone et al 1986) and it remains to be seen whether arthroscopically-assisted rotator-cuff repair can be more effective. The technique has several potential advantages: 1) it is easier to evaluate and treat coexisting glenohumeral lesions; 2) the attachment of the deltoid muscle is preserved; 3) rehabilitation is more rapid and hospital stay is diminished because there is less soft-tissue damage; and 4) the cosmetic result is better than after open repair.

We wish to thank Mr Alexander Raskin, and Drs Harvard Ellman, Champ L. Baker, and Stephen Kay for their contributions to this multicentre study. No benefits in any form have been received or will be received from a commercial party related directly or indirectly to the subject of this article.

\section{REFERENCES}

Burkhart SS. Arthroscopic treatment of massive rotator cuff tears: clinical results and biomechanical rationale. Orthop Trans 1990; 14:173.

Cofield RH. Current concepts review: rotator cuff disease of the shoulder. J Bone Joint Surg [Am] 1985; 67-A:974-9.

Cofield RH, Hofimeyer P, Lanzer WL. Surgical repair of chronic rotator cuff tears. Orthop Trans 1990; 14:251-2.
Ellman H, Hanker G, Bayer M. Repair of the rotator cuff: end result study of factors influencing reconstruction. J Bone Joint Surg [Am] 1986; 68-A:1136-44.

Ellman H, Kay SP. Arthroscopic subacromial decompression for chronic impingement: two to five years results. J Bone Joint Surg [Br] 1991; 73-B:395-8. 
Ellman H, Kay SP, Wirth M. Arthroscopic treatment of full thickness rotator cuff tears: two to seven year follow-up study. Arthroscopy 1993; 9:195-200.

Gartsman GM. Arthroscopic acromioplasty for lesions of the rotator cuff. J Bone Joint Surg [Am] 1990; 72-A:169-80.

Hawkins RJ, Misamore GW, Hobeika PE. Surgery for full-thickness rotator-cuff tears. J Bone Joint Surg [Am] 1985; 67-A:1349-55.

Levy HJ, Uribe JW, Delaney LG. Arthroscopic assisted rotator cuff repair: preliminary results. Arthroscopy 1990; 6:55-60.

Levy HJ, Gardner RD, Lemak $\mathbf{L}$. Arthroscopic subacromial decompression in the treatment of full-thickness rotator cuff tears. Arthroscopy 1991; 7:8-13.

Neviaser SJ, Neviaser RJ, Neviaser TJ. The repair of chronic massive ruptures of the rotator cuff of the shoulder by use of a freeze-dried rotator cuff. J Bone Joint Surg [Am] 1978; 60-A:681-4.
Ogilvie-Harris DJ, Demazière A. Arthroscopic debridement versus open repair for rotator cuff tears: a perspective cohort study. J Bone Joint Surg [Br] 1993; 75-B:416-20.

Post M, Cohen J. Impingement syndrome: a review of late stage II and early stage III lesions. Orthop Trans 1985; 9:48.

Rockwood CA, Burkhead WZ. Management of patients with massive rotator cuff defects by acromioplasty and rotator cuff debridement. Orthop Trans 1988; 12:190-1.

Snyder SJ, Pachelli AF, Del Pizzo, et al. Partial thickness rotator cuff tears: results of arthroscopic treatment. Arthroscopy 1991; 7:1-7.

Tibone JE, Elrod B, Jobe FW, et al. Surgical treatment of tears of the rotator cuff in athletes. J Bone Joint Surg [Am] 1986; 68-A:887-91.

Warner JP, Altchek DW, Warren RF. Arthroscopic management of rotator cuff tears with emphasis on the throwing athlete. Oper Tech Orthop 1991; 1:235-9. 